\title{
A global overview on nuclear desalination
}

\section{Khamis}

\author{
International Atomic Energy Agency (IAEA) \\ Wagramer Strasse 5 \\ P.O. Box 100, Vienna A-1400, Austria \\ E-mail: i.khamis@iaea.org
}

\begin{abstract}
Nuclear desalination is considered one of the viable sources of producing the fresh water needed in arid areas. Nowadays, several countries have shown interest in the use of nuclear energy for seawater desalination, because recent studies have demonstrated that nuclear desalination is not only feasible but also economical, and this has already been demonstrated in several countries. Although the future requires the effective integration of energy resources to produce power and desalinated water economically with proper consideration for the environment, the significant increase in fuel energy cost and material cost has resulted in a dramatic impact on the capital and operational costs of desalination and power plants. The impact of any increase in the price of fossil fuels (as in the case before mid-2008) and the high demand for raw materials (e.g., steel, copper, nickel) will increase the pressure to develop novel solutions to minimise fossil energy consumption and reduce the capital expenditure of desalination plants. This, in turn, is causing a renewed global interest in nuclear energy. However, nuclear desalination may face some challenges, among which are public perception, financing, the transfer of nuclear technology and considerations for the safety of the coupling options selected.
\end{abstract}

Keywords: nuclear desalination; outlook; trends; desalination technologies; fresh water supply.

Reference to this paper should be made as follows: Khamis, I. (2009) 'A global overview on nuclear desalination', Int. J. Nuclear Desalination, Vol. 3, No. 4, pp.311-328.

Biographical notes: I. Khamis earned his MSc in 1986 and his PhD in 1988 in Nuclear Engineering from the University of Arizona, Tucson, Arizona, USA. Since 2006, he has been the Project Manager for nonelectric applications of nuclear energy at the Nuclear Power Technology Development Section, Division of Nuclear Power, IAEA. His duties involve nuclear desalination, hydrogen production, district heating and other industrial applications of nuclear energy. Prior to joining the agency, he was the Head of the Nuclear Engineering Department, Atomic Energy Commission, Damascus, Syria. He served as a Consultant and member of several national and Arab committees on reactor technology and water desalination. He is the author or co-author of more than 70 research publications and conference presentations. His main interests are reactor physics, design and simulation, and nonelectric applications of nuclear energy.

Copyright @ 2009 Inderscience Enterprises Ltd. 


\section{Introduction}

The reliable supply of water and energy is an important prerequisite for sustainable development. As a global issue, water scarcity is affecting more countries every year. The contracted capacity of desalination plants has increased steadily since 1965 and is reported to have reached an almost 40 million $\mathrm{m}^{3} / \mathrm{d}$ worldwide (International Atomic Energy Agency, 2007c). During the past few years, a large number of reactors have been planned in many developing countries owing to their increasing energy demands and their meagre fossil sources (International Atomic Energy Agency, 2008c). New constructions are expected in the USA, Europe and Asia as well.

Desalination in general, and nuclear seawater desalination in particular, provides hope to the world community that water, the essence of life, can be provided at reasonable costs (International Atomic Energy Agency, 2007a). Unlike oil, fresh water has no viable substitute. Therefore, desalination is one of the major resources for solving the scarcity of existing water supplies, avoiding regional and territorial conflicts, and providing the water resource for sustainable development. Seawater desalination, with a reliability which has decisively been proven during the last four decades, could deliver large amounts of drinking water from the sea.

The integrated use of technology can compensate for the impact of the rising cost of energy and materials. As desalination and water reuse expansion in the world continue at a rapid pace, new innovations must be integrated into the next generation of water facilities. Such an innovation, for example, is the use of heat pipes (Jouhara and Robinson, 2009; Jouhara et al., 2007) in heat recovery systems, i.e., as heat exchangers in nuclear and fossil desalination systems. Indeed, the future requires such an effective integration of energy resources to produce power and desalinated water economically, with proper consideration for the environment. It is estimated that, to produce fresh water at the present desalination capacity using nuclear energy, the needed nuclear capacity would be about forty 1000-MWe nuclear reactors (International Atomic Energy Agency, 2009b).

The significant increase in fuel energy cost and material cost has a dramatic impact on the capital and operational costs of desalination and power plants. In fact, any sharp increase in oil prices similar to the one reached before mid-2008 (and an equivalent increase in the price of gas) and the increased demand for raw materials (i.e., of steel, copper, nickel) will dramatically increase the pressure to develop novel solutions to minimise fossil energy consumption and reduce the capital expenditure of desalination plants (International Atomic Energy Agency, 1990; 1992; 1996a-b). All of these, as well as the recent levelised cost estimate of electricity generation technologies (see Figure 1), (International Atomic Energy Agency, 2008b) lead to renewed global interest in nuclear energy as an energy source for desalination.

The need for environmental protection (Younos, 2005), together with the security of energy supply that nuclear power is offering, has led many countries to renew discussion about the nuclear power option to meet increasing energy and electricity demands. In particular, this is observed to be emerging in developing countries (International Atomic Energy Agency, 1996b; Misra, 2007). Unfortunately, most of these countries, which are suffering from water scarcity, are generally not the holders of nuclear technology. The introduction of nuclear energy in such countries will require due consideration and assessment of institutional and infrastructure aspects before a decision on the Nuclear 
Power Plant (NPP) is made. These aspects include arrangements for plant licensing, construction, financing, the signature of international conventions/agreements for the fuel cycle, starting with the acquisition of fresh fuel to the management of spent fuel (International Atomic Energy Agency, 2006a-b; 2007b; 2009a).

Figure 1 Levelised cost estimate of electricity generation technologies (see online version for colours)

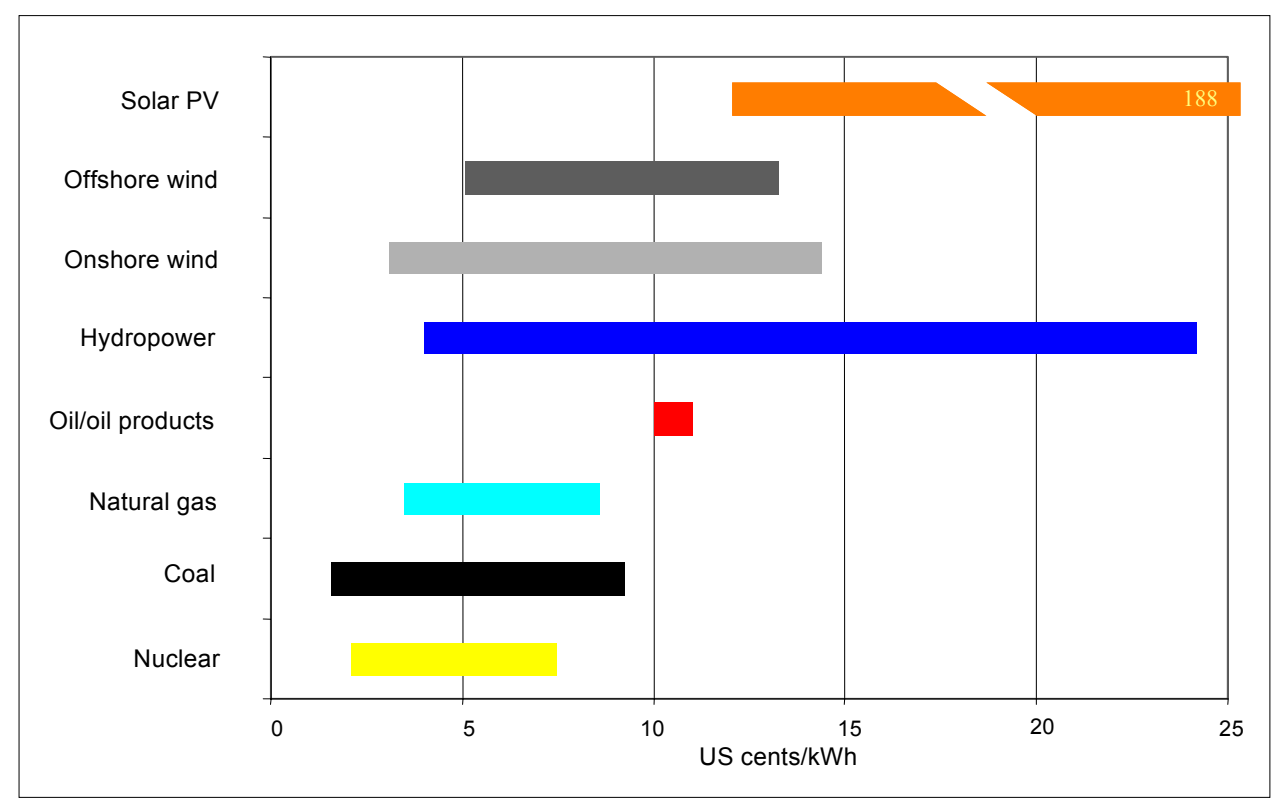

In this paper, the current trends and future outlook of nuclear desalination are highlighted as a summary of the issues discussed during the international conference Non-electric Applications of Nuclear Power, which was organised by International Atomic Energy Agency at Oarai, Japan, on 16-19 April 2007, and of the results of the recently completed coordinated research project 'Economics research on, and assessment of, selected nuclear desalination projects and case studies'. Therefore, this paper presents an overview of the nuclear desalination aspects including a brief energy outlook and prospects for nuclear desalination.

\section{Nuclear energy outlook}

The world energy requirements are presently met from oil, coal, gas, hydro, nuclear and renewable energies (EIA, 2008) in that order, as shown in Table 1. 
Table 1 World energy use

\begin{tabular}{lcl}
\hline Fuel & Percentage (\%) & Present trends \\
\hline Oil & 39 & $\begin{array}{l}\text { Short term: building of additional plants continues } \\
\text { Coal }\end{array}$ \\
Gas & 25 & $\begin{array}{l}\text { Suilding of additional plants continues } \\
\text { Short-term: building of additional plants continues; gas } \\
\text { turbine combined cycle plants considered the cheapest of } \\
\text { fossil-fuelled plants }\end{array}$ \\
$\begin{array}{l}\text { Hydro } \\
\text { Nuclear }\end{array}$ & 7 & $\begin{array}{l}\text { Building of dams continues, where possible } \\
\text { More or less stagnant in developed countries, with hope for } \\
\text { renewed interest; high rate of expansion in emerging countries } \\
\text { Gradual expansion; continued efforts to reduce costs }\end{array}$ \\
$\begin{array}{l}\text { Renewable } \\
\text { energies }\end{array}$ & 1 & \\
\hline
\end{tabular}

The Worldwide Desalination Inventory Report states that a total of 17348 desalting units (with a total capacity of $37750000 \mathrm{~m}^{3} / \mathrm{d}$ or 8.3 billion imperial gallons per day) have been installed or contracted. Desalination is already used in 125 countries around the world (Wangnick Consulting, 2001; 2004; World Water Vision, 2000). Desalination has decisively proven, during the last 30 years, its reliability to deliver large quantities of fresh water from the sea (Sommariva and McDonald, 2003). For nuclear desalination to be attractive in any given country, two factors must be simultaneously in place: a lack of water and the ability to use nuclear energy for desalination. In most regions, only one of the two is present. Both are present in, for example, China, the Republic of Korea and, even more so, India and Pakistan. These regions already account for almost half the world's population and thus represent a potential long-term market for nuclear desalination. The market will expand further to the extent that regions with high projected water needs, such as the Middle East and North Africa, increase their nuclear expertise and capabilities. Many of the countries in these regions already have large-scale desalination plants based on fossil sources. The future of desalination in the water-stressed regions of the USA, i.e., in California, Texas and Florida, focuses on two objectives (WWDmag.com, 2007):

1 a short-term objective aiming to achieve a $20 \%$ improvement in costs and energy efficiency

2 a long-term objective to achieve up to $80 \%$ improvements, to be realised around 2030.

Although no nuclear reactors have been utilised so far for electricity production in the Middle East region, dual use and other applications of nuclear reactors have now been exploited. Oil and gas reserves in the Middle East make up more than $70 \%$ of world resources, which may be one of the reasons for not giving priority to nuclear energy as an option. The socioeconomic aspects of nuclear applications are favourable when compared and judged against conventional, nonnuclear competitors on cost, reliability, safety, simplicity and sustainability. When considering these applications, nuclear energy has priority not only in energy supply, but also in health, industry and agriculture. 
Nuclear energy is a clean, safe, powerful and greenhouse gas emission-free option to help meet the world's demand for energy. It still has the unexploited potential of producing process heat and steam in a broad temperature range. There is experience with nuclear energy in the heat and steam markets in the low temperature range (International Atomic Energy Agency, 1997; 2008a; 2000c). An extension appears possible in the short term in the areas of desalination, district heating and tertiary oil recovery. In the higher-temperature heat/steam range, there exists a significant potential for nuclear energy in the area of hydrogen production and in the petrochemical industries, including the production of liquid fuels for the transportation sector. It still needs, however, a broader deployment of the respective nuclear heat sources. The use of reject heat from gas-cooled reactors with helium turbines provides a promising option for economical nuclear desalination by Pebble Bed Modular Reactors (PBMRs) for near-term deployment and the Very High Temperature Reactors (VHTRs) of Gen IV in the future (International Atomic Energy Agency, 2000a; 2002).

The main features of nuclear energy are a mature technology, a nearly carbon-free electricity generation source, stable and low costs, geopolitical distribution of uranium resources and a domestic source of energy (International Atomic Energy Agency, 2000b). The existing NPPs have a steady return of profits for most utilities worldwide. A considerable change in the view of the capital markets in the last two years on nuclear not being that capital intensive is quite encouraging. Economic competitiveness is no longer an issue. A large number of reactors are planned in many developing countries with increasing energy demand and meagre fossil sources. Capital markets expect new construction in some countries of Europe too. Resources to invest in new NPPs are available.

Today, $14 \%-15 \%$ of world electricity is generated by NPPs. There are 438 nuclear reactors operating in 30 countries (International Atomic Energy Agency, 2008d). The existing power plants are competitive; their load factors have remained high. Upgrading of plant capacities in a number of power plants has also taken place or is planned. A number of older reactors are scheduled for lifetime extension as it is found to be economical. Nuclear power generation is a mature technology. More than 10000 reactor-years of operating experience have been accumulated over the past five decades. Thus, there are many reasons which favour a revival of nuclear power production in the years to come (International Atomic Energy Agency, 2000b).

However, times are changing due to concerns on the rising of fossil fuel prices, security of energy supply (and diversity) and climate change. More favourable policies on nuclear could significantly accelerate the growth in global capacity especially in Organisation for Economic Co-operation and Development (OECD) countries (EIA, 2008). Figure 2 shows the world nuclear capacity in the Reference and Alternative Policy Scenarios (RS and APS respectively) from 2005 to 2030 for OECD countries, transition economies and developing countries (International Atomic Energy Agency, 2009b). Figure 3 shows the countries with nuclear power and most importantly those considering nuclear power and planning a massive expansion of their capacities. 
Figure 2 World nuclear capacity in the reference and alternative policy scenarios (see online version for colours)

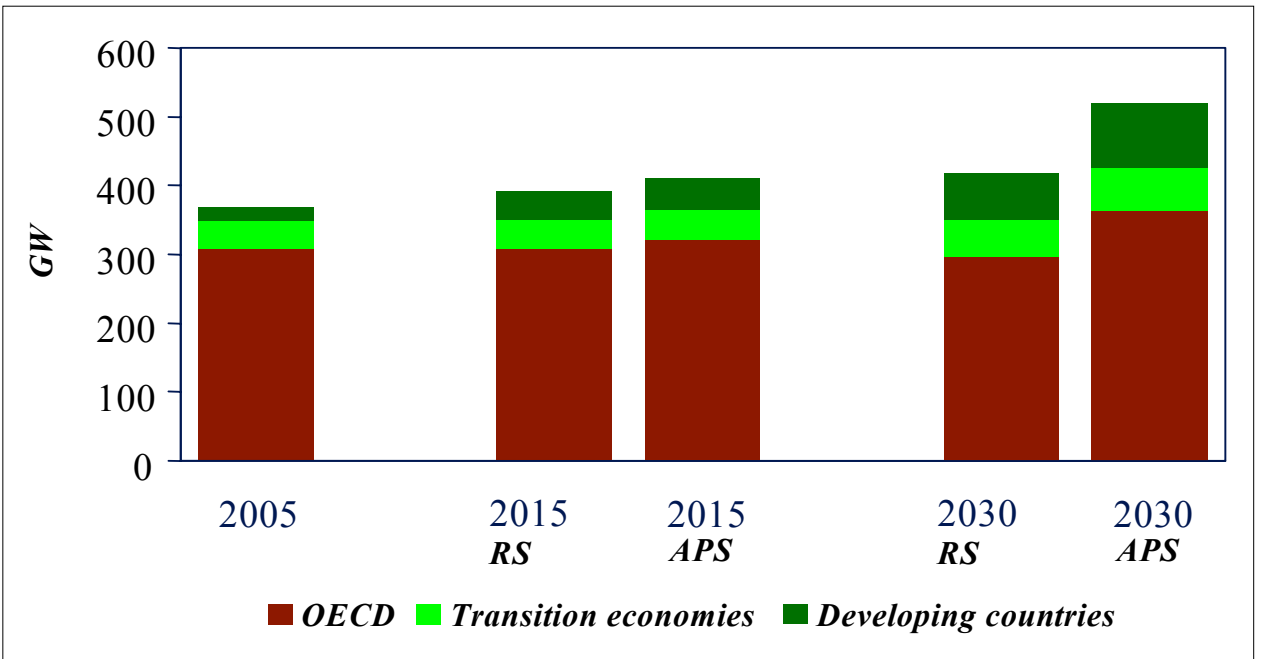

Figure 3 Countries considering the introduction/expansion of nuclear power (see online version for colours)

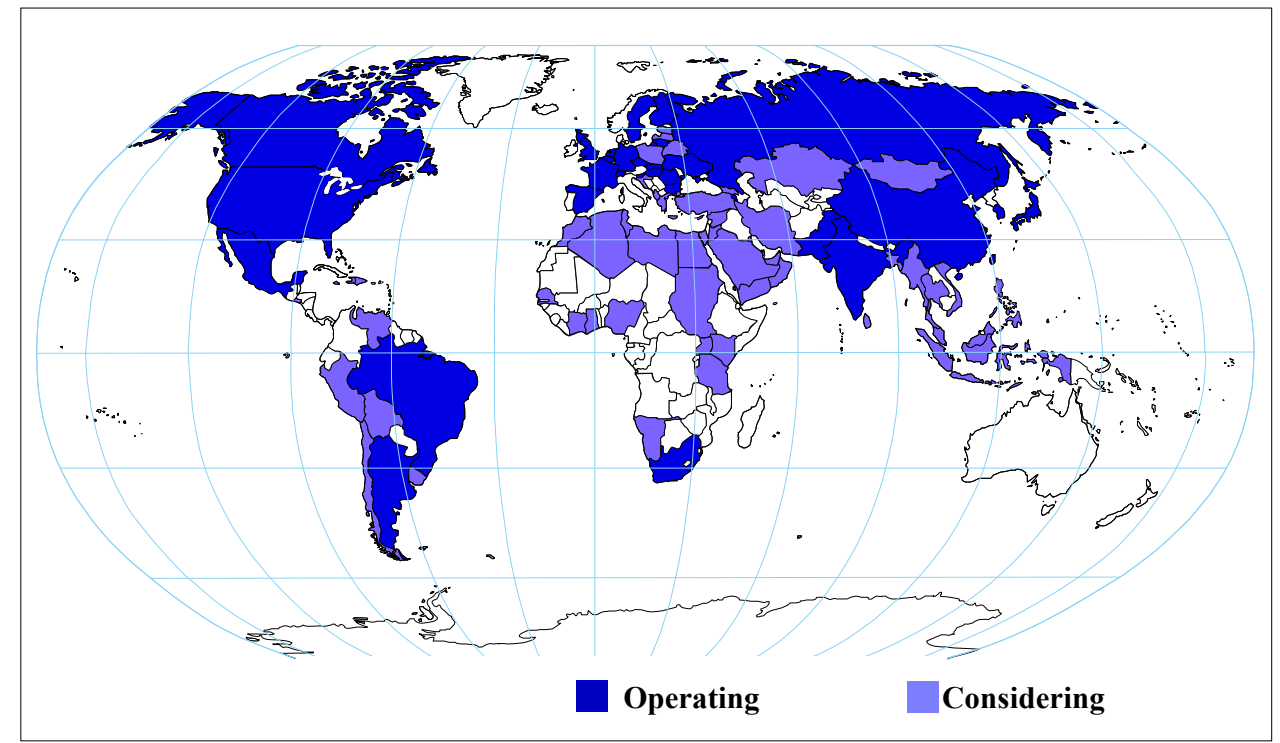

\section{Prospects for nuclear seawater desalination}

Since nuclear energy is a nearly carbon-free generation option, a long-term sustainable solution and potentially competitive with fossil fuels, it is necessary to consider it a choice for desalination projects. This is true particularly in cases when power and heat for desalination are generated using heavy crude oil or coal, which require significant costs 
for pollution control and are thus inefficient generation solutions, resulting in a significant increase in the penalty for $\mathrm{CO}_{2}$ emission and greenhouse impact (International Atomic Energy Agency, 2008b). Indeed, there are many opportunity factors for nuclear desalination such as the following:

- the overall cost of fossil heat generation is being dominated by the cost of fuel itself

- the current trends in fossil fuel prices and supply uncertainties

- concerns about GHG emissions

- concerns that the new generation of NPP systems have highly enhanced safety levels and competitive economics.

An important example for the potential use of nuclear energy in the low-temperature range is seawater desalination, a process with increasing importance due to growing drinking water shortage in many arid areas in the world. The integration of energy, power and water becomes even more important today in coping with the increased costs. The desalination technology has to adapt to the new conditions and find solutions to produce plants with higher efficiency, performance ratios and minimised use of materials. The assurance of drinking water supply demands creative solutions (International Atomic Energy Agency, 2007a). It requires effective innovations and the integration of energy resources to generate power and to economically create and store desalinated water. Confronting the water challenge is essential to a country's sustainable development and to the security of its communities. Desalination is the only realistic hope for creating new water resources in the midst of the water crisis and water pollution. The need to innovate and integrate energy, power and water does exist. New ideas on hybridisation, energy recovery, and more effective materials and chemicals should be pursued (International Atomic Energy Agency, 2007a).

The principal desalination processes are based either on distillation or on membrane separation. The first group includes the widely applied commercial methods of Multi-Stage Flash Distillation (MSF) and Multiple Effect Distillation (MED). Still under development is the Thermal Vapour Compression (TVC) distillation, which is a promising process with a higher conversion ratio. The main characteristics of distillation processes are a high energy cost, independence from feed water quality and a simple technology with wide experience worldwide. The membrane processes are characterised as having lower energy costs, being dependent on the feed water quality and simplicity. Major thermal energy in the range of $100^{\circ} \mathrm{C}-130^{\circ} \mathrm{C}$ is required to heat the feed water. Since a low-temperature heat input is sufficient, an economic and preferable constellation is operation in a heat and power cogeneration plant, which benefits from the added value of electricity sales (International Atomic Energy Agency, 2007a; Spadaro et al., 2000).

Seawater desalination is an energy- and capital-intensive process. All seawater desalting processes - MSF, MED and Seawater Reverse Osmosis (SWRO) - consume significant amounts of energy and materials. In view of the rising fuel costs, the amount and cost of fuel consumed to desalinate seawater become some of the main factors determining the operational cost of water desalination. Similarly, the materials selected and the increased cost of materials for desalination have a significant impact on the capital cost. These rising costs, in turn, become a major factor in choosing the method and technology to be used (Tewari and Rao, 2002). The Reverse Osmosis (RO) process employs a pressure-driven separation technique where water is forced under high 
pressure through a water-permeable membrane. No heating or phase change takes place. The main energy is the electricity required for the initial pressurisation of the feed water, 5-7 MPa for seawater or 2-3 MPa for brackish water. The advantages are a simple processing and low installation and maintenance costs. The drawbacks are the necessary pretreatment of the feed water, the short lifetime of the membranes and the comparatively high content $(1 \%-2 \%)$ of salt passing through the membrane (Spadaro et al., 2000; Tewari and Rao, 2002).

There has been limited experience with nuclear desalination since the 1960s, coming from nine nuclear units in Japan and one in Kazakhstan. The latter was a BN-350 fast reactor which produced $135 \mathrm{MW}(\mathrm{e})$ and $80000 \mathrm{~m}^{3} / \mathrm{d}$ of fresh water by MED over 27 years before it was taken out of operation in 1999 (International Atomic Energy Agency, 2007a). In Japan, the desalination plants are constructed on-site at the NPPs with the aim of supplying the required makeup cooling water to these NPPs. Such desalination plants have small capacities of $1000-3000 \mathrm{~m}^{3} / \mathrm{d}$ in general. In India, a combined MSF and RO hybrid system connected to twin $170 \mathrm{MW}(\mathrm{e})$ pressurised heavy water reactors has been constructed and is presently in the commissioning phase. With capacities of $1800 \mathrm{~m}^{3} / \mathrm{d}$ by RO and $4500 \mathrm{~m}^{3} / \mathrm{d}$ by MSF, it will become the largest nuclear-based desalination plant in the world (Tewari and Khamis, 2007). The nuclear-driven process is technically and economically feasible (the EURODESAL project (Tewari, 2007)), but is yet to be demonstrated on a larger industrial scale. The optimisation of water desalination using nuclear reactors has been analysed (Lacomte and Bandelier, 2002) and the project's studies are under investigation in several countries (Tewari and Khamis, 2007).

As desalination and water reuse expansion in the Middle East and the world continues at a rapid pace, these innovations must be integrated into the next generation of water facilities. The integrated nuclear energy systems would lead to considerably lower power and water costs than the corresponding coal-based systems. When external costs for different energies are internalised in power and water costs, the relative cost differences are considerably increased in favour of the nuclear systems. Financial analysis further confirms these conclusions (Nisan et al., 2007; Wade, 2001). Integrated seawater desalination systems are likely to be deployed intensively in the future in view of the very high demands for water and electrical energy in many regions of the world. A future desalination strategy based uniquely on the utilisation of fossil-fuelled systems is not sustainable because of the high carbon footprint from both power generation and desalination. At the moment, the only solution to reduce the carbon footprint of integrated desalination systems appears to be by utilising nuclear and renewable energies (International Atomic Energy Agency, 2008b).

\section{Global nuclear desalination activities}

Worldwide, the accumulated operating experience of nuclear desalination has exceeded 200 reactor-years. All nuclear reactor types can provide the energy required by the various desalination processes. However, Small and Medium Reactors (SMRs) may offer, when available, the largest potential as coupling options to nuclear desalination systems in developing countries ( $\mathrm{Li}$ et al., 2003; Wade, 2001). The development of 
innovative reactor concepts and fuel cycles with enhanced safety features as well as their attractive economics are expected to improve public acceptance and further the prospects of nuclear desalination.

The coupling with nuclear systems is not difficult technically (International Atomic Energy Agency, 2001; Methnani, 2003) but needs some consideration in the following:

- avoiding radioactivity cross-contamination

- $\quad$ providing backup heating energy sources in case the nuclear system is not in operation (e.g., for refuelling and maintenance)

- incorporating certain design features in case the thermal desalination option is used.

Japan has over 150 reactor-years of nuclear-powered desalination experience. Kazakhstan had accumulated 26 reactor-years before shutting down the Aktau fast reactor (BN-350) at the end of its lifetime in 1999. In India, a low-temperature desalination plant using the waste heat of a nuclear research reactor has been operating since 2004. Information on reactor type, location, desalination process and status for nuclear desalination are given in Table 2.

Table 2 Nuclear desalination systems including reactor types and desalination processes

\begin{tabular}{|c|c|c|c|}
\hline $\begin{array}{l}\text { Reactor } \\
\text { type }\end{array}$ & Location & $\begin{array}{l}\text { Desalination } \\
\text { process }\end{array}$ & Status \\
\hline LMFR & Kazakhstan (Aktau) & MED, MSF & In service till 1999 \\
\hline \multirow[t]{5}{*}{ PWRs } & $\begin{array}{l}\text { Japan (Ohi, Takahama, } \\
\text { Ikata, Genkai) }\end{array}$ & MED, MSF, RO & $\begin{array}{l}\text { In service with operating experience } \\
\text { of over } 150 \text { reactor-years }\end{array}$ \\
\hline & Rep. of Korea & MED & \multirow{2}{*}{$\begin{array}{l}\text { Integral SMRs of the PWR type; } \\
\text { under design or to be constructed }\end{array}$} \\
\hline & Argentina & RO & \\
\hline & Russia & MED, RO & $\begin{array}{l}\text { Under consideration (barge-mounted } \\
\text { floating unit with the KLT-40) }\end{array}$ \\
\hline & USA (Diabolo Canyon) & RO & Operating \\
\hline BWR & Japan (Kashiwazaki-Kariva) & MSF & $\begin{array}{l}\text { Never in service following testing in } \\
\text { 1980s, due to alternative fresh water } \\
\text { sources; dismantled in } 1999\end{array}$ \\
\hline \multirow[t]{3}{*}{ HWR } & India (Kalpakkam) & $\mathrm{MSF} / \mathrm{RO}$ & Under commissioning \\
\hline & India (Trombay) & LT-MED & In service since 2004 \\
\hline & Pakistan (KANUPP) & MED & $\begin{array}{l}\text { Existing CANDU modified to } \\
\text { be coupled to an MED plant } \\
\text { (under construction) }\end{array}$ \\
\hline NHR-200 & China & MED & $\begin{array}{l}\text { Dedicated heat-only integral PWR; } \\
\text { under design }\end{array}$ \\
\hline HTRs & $\begin{array}{l}\text { France, The Netherlands, } \\
\text { South Africa }\end{array}$ & MED, RO & $\begin{array}{l}\text { ANTARES, multipurpose reactor, } \\
\text { GT-MHR and PBMR; under } \\
\text { development and design }\end{array}$ \\
\hline
\end{tabular}




\section{Economics of nuclear seawater desalination}

Seawater desalination is expected to create sustainable development for extra water resources, become the only available choice to meet the increasing water demand in the future, help minimise regional and international conflicts over the sharing of water, and offer a commercial opportunity of 80 billion USD plus, all in the next 10-20 years. The results show that, in all conditions, the nuclear desalination options cost $10 \%$ to $15 \%$ lower than the cheapest of fossil-fuelled options: the coal fired plant CFB-900, using state-of-the-art improvements and current coal prices of $60 \$ / t$. Internalisation of the external costs hardly affects the power and desalination costs of nuclear systems but strongly influences those of the fossil-fuelled systems.

Figure 4 shows (Wangnick Consulting, 2004) the water costs from global seawater desalination and conventional production (in various countries). The costs of seawater desalination are already comparable to conventional water costs in water-scarce/ water-starved countries, and likely to approach each other even in countries having cheap and abundant water sources.

Figure 4 Development of water costs (see online version for colours)

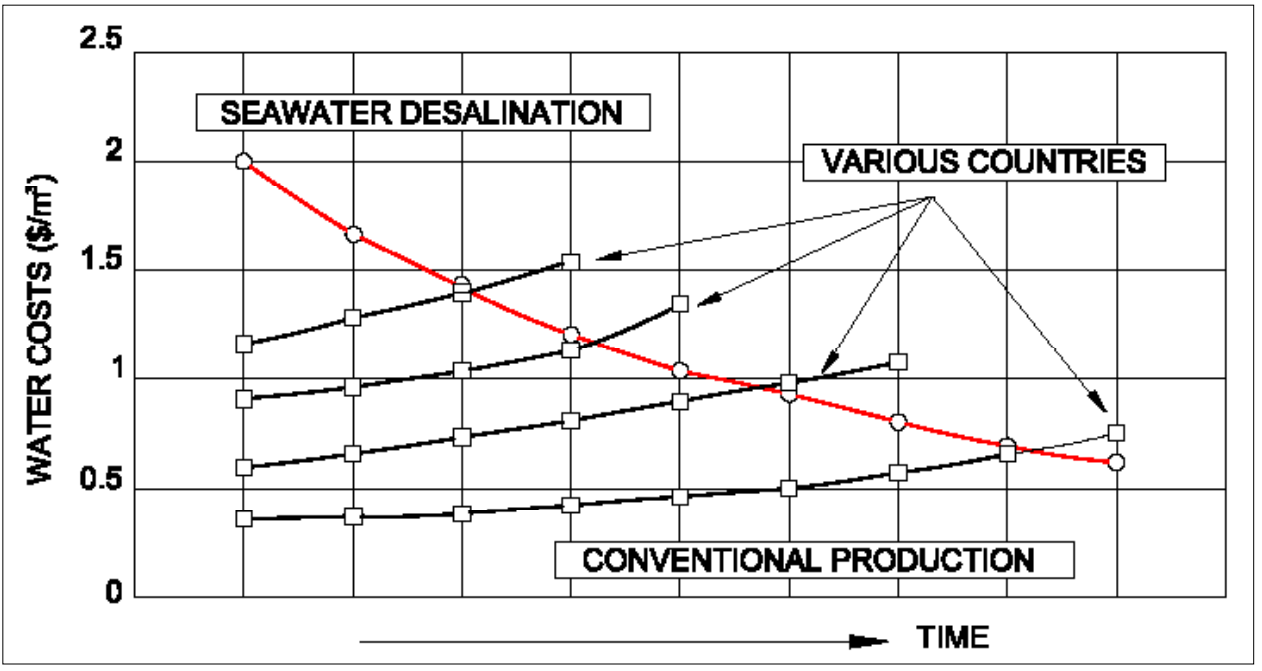

There are several factors which may affect desalination costs and thus determine the successful implementation of desalination systems using nuclear or other energies. These factors include site characteristics, plant capacity and feed water quality. The selection of power plant and desalination plant combinations for cogeneration (simultaneous production of power and water) depends on several factors, of which the most important one is the Water-to-Power (W/P) ratio, defined as the ratio of the total water production capacity $\left(\mathrm{m}^{3} /\right.$ day) and the $\mathrm{MW}(\mathrm{e})$ of the power produced (International Atomic Energy Agency, 2007a). The other factors include the desalination plant's energy consumption, the power plant's specific fuel consumption, the effect of seasonal loads and the specific investment costs of the water and power plants. 
Nuclear reactors are capable of providing electrical and/or thermal energy once coupled to an appropriate desalination process (Hanra, 2000). The reactors can operate as dedicated (single-purpose) systems, producing only desalted water, or as cogeneration (dual purpose) systems, producing both water and electricity. Single-purpose nuclear desalination systems are considered more suitable for remote isolated regions. The fundamental role of the economic evaluation of any engineering project is to enable coherent comparisons with alternative options, to prepare the financing details for the implementation of the project, to fix tariffs and, finally, to furnish a clear choice of options to decision makers (Bouzguenda et al., 2006).

In general, the deployment of nuclear energy takes a rather long time. In most emerging and developing countries, such a deployment continues to have a slow trend (except in China and India) for several and in some cases complex reasons, the most important of which is the considerable difficulties that such countries encounter in finding adequate financing for nuclear projects (International Atomic Energy Agency, 2009a). The relatively high investment cost of nuclear reactors with the associated uncertainties and risks (International Atomic Energy Agency, 2007c) and the relatively longer construction lead times are two main factors of the high cost. In some countries additional investment has to be made, such as in the construction of roads and adequate transport, the development of large-enough ports to receive heavy material, the development of infrastructures, the preparation of the site, including facilities for the personnel, etc.

New developments in nuclear desalination are progressing forward as many member states have consistently progressed almost simultaneously in the three technical fields: the development of improved/new-generation nuclear reactors, the improvements in desalination technologies and the adoption of several cost-reduction strategies (International Atomic Energy Agency, 2007a; Pankratz, 2001). These developments have been discussed in detail in the recent IAEA publication Status of Nuclear Desalination in Member States (International Atomic Energy Agency, 2007c). For example, Argentina is developing the CAREM reactor, which is a small integral-type PWR. China is pursuing the development of a dedicated heat-only reactor, NHR-200, providing relatively low-temperature heat for a MED process, with some electricity production to meet the local electricity needs. India is going along with a consistent evolutionary approach to develop its advanced PHWRs. The Republic of Korea continues with its programme to develop the System-integrated Modular Advanced Reactor (SMART), which is a small (330 MWth) integral-type PWR, containing all major primary components in a single pressurised vessel. SMART is designed to produce about $40000 \mathrm{~m}^{3} /$ day of potable water.

\section{New trends in the desalination processes}

Whether thermal or membrane-based processes, desalination technologies have shown continued progress over the past decades (International Atomic Energy Agency, 2007c; 2007a). The emphasis was mainly on cost reduction strategies through technological innovations. 


\subsection{Thermal processes}

The thermal desalination process produces distilled-quality water. New developments in the thermal processes can be summarised as follows:

- a High-Gain Output Ratio (GOR)

- choice of high-performance materials, development of high-heat-transfer alloys for the tubes, increasing use of nonmetallic evaporator materials

- improvement in corrosion resistance (e.g., utilisation of antiscaling organic products)

- improvements in availability and thermodynamic efficiencies, due to the incorporation of online cleaning procedures

- modular construction, with improvements in fabrication procedures, reducing construction lead times

- development of efficient and more precise process control systems and procedures.

\subsection{Membrane-based technologies}

RO-based plants are rapidly expanding systems in today's desalination markets. Membrane-based systems have become the cornerstone of the strategies for water recycling and recovery. Among the notable advances in membrane desalination are:

- an increase in salt rejection efficiency (from 98\% to 99.8\%)

- increase in permeate flux

- enhanced chlorine tolerance

- reduction of the costs of cleaning and pretreatment requirements

- development of longer life membranes

- membrane-based pretreatment

- efficient energy-recovery devices.

\section{Cost reduction strategies in nuclear desalination}

Energy cost represents a substantial fraction of the total desalination costs. Although desalination processes have been, and continue to be, considerably improved, there is a strong incentive to further reduce desalination costs. Several approaches are currently under investigation.

\subsection{Utilisation of waste heat from nuclear reactors}

Commonly used desalination processes are the MSF, MED and RO. In all these cases, part of the useful energy is drawn from the nuclear power station to produce the desalted water. If the desalting capacity is high, this energy loss could be very significant. 
An alternative, providing virtually free heat to be used with the MED process, is based on the utilisation of gas-cooled, high-temperature reactors with helium turbines based on the Brayton cycle. Two gas-cooled reactors of that type are under development, the Gas Turbine-Modular Helium Reactor (GT-MHR) and the PBMR with circulating helium. The helium has to be compressed in two successive stages before it cools the reactor core. For thermodynamic reasons, these compression stages require precooling of the helium from more than $100^{\circ} \mathrm{C}$ to about $26^{\circ} \mathrm{C}$ through the use of the precooler and intercooler helium-water heat exchangers. Considerable thermal power (about $300 \mathrm{MWth}$ ) is thus dissipated in the precooler and the intercooler. This thermal power is then evacuated to the heat sink.

Depending upon the specific designs, the temperature ranges of the water in these heat exchangers could be between $80^{\circ} \mathrm{C}$ and $130^{\circ} \mathrm{C}$. This is an ideal range for desalination with the MED plant, which can be coupled between a mixer (of the flows from the precooler and the intercooler) and the switch-cooling unit, which evacuates the heat to the heat sink (the sea or river).

The net electrical efficiencies of the power conversion systems in current PWRs and CANDUs are in the order of $30 \%$ to $33 \%$. This means that nearly two-thirds of the net thermal power produced in the reactors is removed by the condensers. In case of seawater cooling, the relatively warm seawater from the condenser outlet can be fed to an innovative variant of the RO process, with preheating known as the ROph process. In hybrid systems, it is also possible to use the cooling seawater return stream from the thermal desalination component as the feed to the RO component. It is observed that ROph can lead to a desalination cost reduction of about $14 \%$ compared to the desalination cost of a conventional RO system. This reduction is independent of the power source.

In the $500 \mathrm{MWe}$ Indian PHWR, the heavy-water moderator in the moderator tank is cooled from $80^{\circ} \mathrm{C}$ to $55^{\circ} \mathrm{C}$ by process water, which in turn is cooled from $55^{\circ} \mathrm{C}$ to $35^{\circ} \mathrm{C}$ by seawater, which enters at $32^{\circ} \mathrm{C}$ and leaves at $42^{\circ} \mathrm{C}$. About $100 \mathrm{MW}$ th is thus available as usable heat for seawater desalination. The details have been worked out using a process water temperature of $55^{\circ} \mathrm{C}$ to avoid any changes in the moderator system. The nuclear desalination system produces about $1000 \mathrm{~m}^{3} /$ day of desalted pure water, which is about $25 \%$ more than the total makeup demineralised (DM) water requirements of the 500 MWe PHWR. It is more economical to use this water as makeup DM water as the thermal energy cost for the LT-MED plant is zero, since it only uses waste heat. Direct production of distilled water eliminates the need for demineralisers and regeneration chemicals. The raw water, otherwise used as feed for the DM plant, can be made available for other purposes, e.g., drinking.

Nuclear research reactors produce significant quantities of waste heat. A scheme was developed at BARC (India) to integrate a desalination unit such that the technology of utilising reactor waste heat for the desalination of seawater by a Low-Temperature Evaporation (LTE) process is demonstrated (International Atomic Energy Agency, 2007a; Tewari and Khamis, 2007). The integrated system has been successfully operated and has clearly demonstrated the technical fesibility of the coupling to the nuclear research reactor. The product water from the plant meets the makeup water requirement of the Indian nuclear research reactor CIRUS. The data from this plant will be useful for the design of larger LT-MED seawater desalination plants for the production of DM water and process water. This plant type is envisaged to be coupled to the Advanced 
Heavy Water Reactor (AHWR) to utilise low-grade/waste heat from AHWR and produce $500 \mathrm{~m}^{3} /$ day distilled-quality water from seawater to meet the DM water makeup requirement of the reactor.

\subsection{Utilisation of hybrid systems}

Optimised hybrid systems using RO and MED can lead to a considerable flexibility of water quality for various applications. Hence, the costs of such hybrid systems could be in the same order as those of stand-alone RO systems.

Hybrid technologies offer part of the solution to another regional problem - water storage. Most countries have a water storage capacity to meet only one day's demand. Installing a water storage capacity at integrated sites would allow the provision of water in winter, which could then be consumed in summer during peak demand.

A relatively new trend in the cogeneration of power and water using desalination involves the coupling of a hybrid seawater desalination plant with a steam-producing power plant. A hybrid desalination plant consists of a combination of thermal and membrane desalination units. The hybrid system has several advantages, such as a shared and smaller seawater intake system, utilisation of a higher feed water temperature to the RO plant for improved performance and the possibility to blend RO and thermal plant product water to obtain a range of product water grades (distilled and drinking quality). It has the ability to use the seasonal surplus of idle power and diversify steam/power allocations and the potential to decrease fuel costs by using the less-energy-consuming RO plant. Other advantages of a hybrid desalination system are:

- the ability to blend and dilute discharged concentrates with the power plant cooling water

- combined seawater pretreatment and product posttreatment systems.

Hybrid desalination systems appear very promising for seawater desalination (International Atomic Energy Agency, 2007a) (see Figure 4). The hybrid system leads to cost savings due to a smaller seawater and reject disposal system, the advantages of preheating the feed to the RO plant, and blending of the product streams of RO and thermal desalination plants. Other cost savings result from a reduction in water posttreatment needs and an overall increase in plant reliability. The reduced need to pump water directly from the sea to the RO plant due to the partial feed supply from the thermal desalination plant can reduce the overall cost of the supply and discharge system by about $25 \%$ for a 2:1 ratio of RO to the thermal desalination product water capacity. The intake and discharge systems amount to about $7 \%$ for both the thermal and RO plants' total direct capital costs (Tewari and Khamis, 2007).

Preheating the feed to the RO by blending fresh seawater with warm cooling seawater discharge from the thermal desalination plant increases the overall flux through the membranes on one hand (by about $2 \%-3 \%$ per $1{ }^{\circ} \mathrm{C}$ ) and the product water (permeate) salinity (by about $1.25 \%$ per $1{ }^{\circ} \mathrm{C}$ ) on the other. Thus, careful attention must be given to the ratio of feed seawater blending to achieve the desired product quality and not to exceed the membrane manufacturer's set limit of $45^{\circ} \mathrm{C}$ for RO membrane performance. This temperature limit $\left(45^{\circ} \mathrm{C}\right)$ is especially significant during the summer months, when the inlet seawater temperature is expected to increase relative to the average year-round seawater temperature. 
Figure 5 Example of a hybrid system coupled directly to a power plant (see online version for colours)

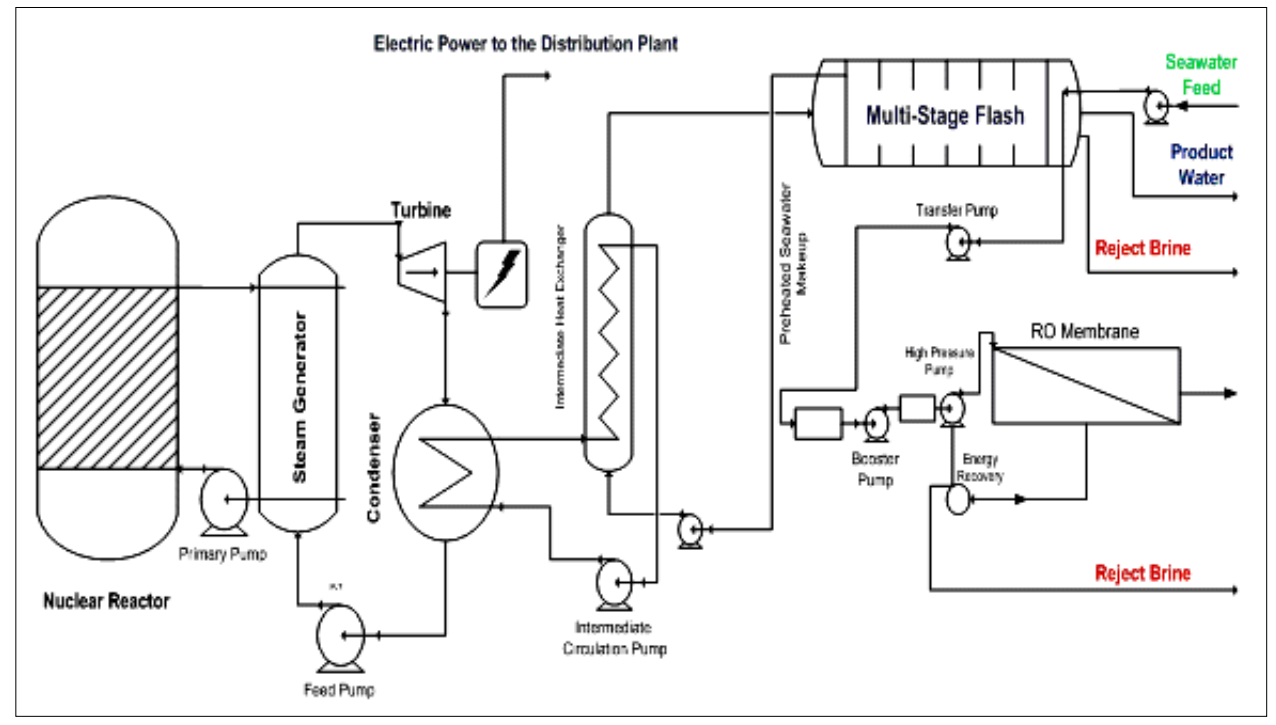

The cost savings due to a reduction in membrane surface area requirements (higher flux) and the related RO plant infrastructure amount to about $10 \%$ of the initial capital cost. The reduction in membrane surface area can reduce the number of membranes required by over $10 \%$ and, thus, reduce overall membrane replacement costs by a similar amount. By blending RO plant product water with the product water of the thermal desalination plant, membrane life can be increased. Membrane replacement can be delayed by up to seven years in some cases by allowing product water from the RO plant to have a higher salinity due to the possibility of blending this poorer-quality water with the high-purity product water $(<10 \mathrm{ppm}$ TDS) of the thermal desalination plant. Thus, the TDS concentration of product water from the RO plant can readily be allowed to exceed the acceptable 500 ppm limit. An increase in membrane life from five (the expected lifetime) to ten years can decrease the need for membrane replacement significantly.

\section{Conclusion}

Nuclear desalination systems are not only technically feasible but economically attractive options in varying site conditions and with a variety of nuclear reactor concepts. Several approaches have been proposed and studied in several countries to reduce the cost of nuclear desalination, such as the use of hybrid thermal/RO systems and the increase in the overall efficiency of the desalination systems through the extraction of valuable materials from the concentrated brine rejected by the desalination plants.

Nuclear desalination costs are strongly influenced by several parameters such as the interest and discount rates, the total plant availability, the power costs and the specific water plant base costs. It should be recalled that the product water salinity by thermal desalination plants is much lower, about $30 \mathrm{ppm}$, compared to the 300 to $500 \mathrm{ppm}$ from RO plants. The real choice of one over the other would thus be a complex problem, 
depending upon the specific industrial, agricultural and potable water needs of the countries. The water transport costs are an essential part of the global picture. These costs should be added to the above production costs to obtain the real cost of desalted water.

The foremost challenge facing nuclear desalination is that the countries suffering from water scarcity are not, generally speaking, the holders of nuclear technology and of the infrastructure for product water distribution (except for China and India). The utilisation of nuclear energy in most countries requires sufficient and qualified human resources, infrastructure building and other institutional arrangements, for example financing. Further challenges of nuclear desalination should be considered seriously, especially those that address issues such as public perception, transfer of nuclear technology and legal infrastructure, including considerations for the safety of the coupling options selected.

\section{References}

Bouzguenda, N., Nisan, S. and Albouy, M. (2006) 'Financing of nuclear desalination projects in developing countries', EUROMED 2006 Conference, Montpellier, France.

Energy Information Administration (EIA) (2008) The International Energy Outlook 2008, DOE/EIA-0484.

Hanra, M.S. (2000) 'Desalination of seawater using nuclear heat', Desalination, Vol. 132, pp.263-268.

International Atomic Energy Agency (1990) Use of Nuclear Reactors for Seawater Desalination, IAEA-TECDOC-574, Vienna.

International Atomic Energy Agency (1992) Technical and Economic Evaluation of Potable Water Production Through Desalination of Seawater by Using Nuclear Energy and Other Means, IAEA-TECDOC-666, Vienna.

International Atomic Energy Agency (1996a) Options Identification Programme for Demonstration of Nuclear Desalination, IAEA-TECDOC-898, Vienna.

International Atomic Energy Agency (1996b) Potential for Nuclear Desalination as a Possible Source of Low Cost Potable Water in North Africa, IAEA-TECDOC-917, Vienna.

International Atomic Energy Agency (1997) 'Nuclear desalination of sea water', Proceeding Series, STI/PUB/1025, Vienna.

International Atomic Energy Agency (2000a) Introduction of Nuclear Desalination: A Guidebook, IAEA Technical Report Series No. 400, Vienna.

International Atomic Energy Agency (2000b) Safety of Nuclear Power Plants: Design: Safety Requirements, IAEA Safety Standard Series No. NS-R-1, Vienna.

International Atomic Energy Agency (2000c) Status of Non-Electric Nuclear Heat Applications: Technology and Safety, IAEA-TECDOC-1184, Vienna.

International Atomic Energy Agency (2001) Safety of Nuclear Plants Coupled with Seawater Desalination Units, IAEA-TECDOC-1235, Vienna.

International Atomic Energy Agency (2002) Status of Design Concepts of Nuclear Desalination Plants, IAEA-TECDOC-1326, Vienna.

International Atomic Energy Agency (2006a) Basic Infrastructure for a Nuclear Power Project, IAEA-TECDOC-1513, Vienna.

International Atomic Energy Agency (2006b) Potential for Sharing Nuclear Power Infrastructure Between Countries, IAEA-TECDOC-1522,Vienna.

International Atomic Energy Agency (2007a) Economics of Nuclear Desalination: New Developments and Site Specific Studies, IAEA-TECDOC-1561, Vienna. 
International Atomic Energy Agency (2007b) Managing the First Nuclear Power Plant Project, IAEA-TECDOC-1555, Vienna.

International Atomic Energy Agency (2007c) Status of Nuclear Desalination in the IAEA Member States, IAEA-TECDOC-1542, Vienna.

International Atomic Energy Agency (2008a) Advanced Application of Water Cooled Nuclear Power Plants, IAEA-TECDOC-1584, Vienna.

International Atomic Energy Agency (2008b) International Status and Prospects of Nuclear Power, IAEA, Vienna, Austria.

International Atomic Energy Agency (2008c) Nuclear Technology Review 2008, Vienna.

International Atomic Energy Agency (2008d) Power Reactor Information System (PRIS) Database, Vienna.

International Atomic Energy Agency (2009a) Issues to Improve the Prospects of Financing Nuclear Power Plants, IAEA Nuclear Energy Series No. NG-T-4.1, Vienna.

International Atomic Energy Agency (2009b) Proceeding of the International Conference on Non-Electric Applications of Nuclear Power: Seawater Desalination, Hydrogen Production and Other Industrial Applications, 16-19 April, Oarai, Japan, Vienna.

Jouhara, H. and Robinson, A.J. (2009) 'An experimental study of small diameter wickless heat pipes operating in the temperature range $200^{\circ} \mathrm{C}$ to $450^{\circ} \mathrm{C}$ ', Heat Transfer Engineering, Vol. 30.

Jouhara, H., Martinet, O. and Robinson, A.J. (2008) 'Experimental study of small diameter thermosyphons charged with water, FC-84, FC-77 \& FC-3283', Proceeding of the 5th European Thermal-Sciences Conference, The Netherlands.

Lacomte, M. and Bandelier, P. (2002) 'Optimization of water desalination by high temperature reactor using electricity/heat cogeneration', Proceedings, International Conference on Nuclear Desalination: Options and Challenges, Marrakech, Morocco, 16-18 October.

Li, T., et al. (2003) 'A comparative economic analysis of the contribution of nuclear seawater desalination to environmental protection using clean development mechanism', Desalination, Vol. 157, pp.289-296.

Methnani, M. (2003) 'Coupling and thermodynamic aspects of seawater desalination using high temperature gas cooled reactors', Proceedings of IDA World Congress on Desalination \& Water Reuse, Bahamas.

Misra, B.M. (2007) 'Seawater desalination using nuclear heat/electricity - prospects and challenges', Desalination, Vol. 205, pp.269-278.

Nisan, S., Alonso, A., Bielak, B., Cinotti, L., Humphries, J.R., Martins, N., Naviglio, A. and Volpi, L. (2007) 'Seawater desalination by nuclear and other energy sources: the EURODESAL project', Nuclear Engineering and Design, Vol. 221, pp.251-275.

Pankratz, T.M. (2001) 'Advances in desalination technologies, nuclear desalination: challenges and options', International Conference, Marrakech, Morocco.

Sommariva, C. and McDonald, M. (2003) Desalination \& Water Reuse Quarterly, Vol. 13, No. 2, pp.13-16.

Spadaro, J., Langlois, L. and Hamilton, B. (2000) 'Greenhouse gas emissions of electricity generation chains: assessing the difference', IAEA Bulletin, Vienna, Vol. 42, No. 2, pp.19-24.

Tewari, P.K. (2007) 'Current activities on nuclear desalination in India', Nuclear India, Vol. 41, Nos. 1-2, pp.22-25.

Tewari, P.K. and Khamis, I. (2007) Proceedings of International Conference on Non-Electrical Applications of Nuclear Power, Oarai, Japan, 16-19 April.

Tewari, P.K. and Rao, I.S. (2002) 'LTE desalination utilizing waste heat from a nuclear research reactor', Desalination, Vol. 150, pp.45-49.

Wade, N.M. (2001) 'Desalination plant development and cost update', Desalination, Vol. 136, pp.3-12. 
Wangnick Consulting (2000) 'IDA worldwide desalting plant inventory', Report No. 16, Gnarrenburg, Germany.

Wangnick Consulting (2004) 'IDA worldwide desalting inventory', Report No. 18, Gnarrenburg, Germany.

World Water Vision (2000) 'Making water everybody's business', World Water Forum, The Hague, The Netherlands, 17-22 March.

WWDmag.com (2007) The Future of Desalination, American Membrane Technology Association, Vol. 4, No. 1.

Younos, T. (2005) 'Environmental issues of desalination', Journal of Contemporary Water Research \& Education, UCOWR, No. 132, pp.11-18. 